\title{
Risk Factors for Tooth Loss Over a 28-year Period
}

\author{
B.A. BURT, A.I. ISMAIL ${ }^{1}$, E.C. MORRISON ${ }^{2}$, and E.D. BELTRAN
}

School of Public Health, The University of Michigan, Ann Arbor, Michigan 48109-2029; ${ }^{1}$ Faculty of Dentistry, Dalhousie University, Halifax, Nova Scotia, Canada; and ${ }^{2}$ University of Texas Health Science Center, Houston, Texas

Over 500 residents of Tecumseh, Michigan, were dentally examined in 1959 as part of a community-wide health study. In 1987, the dental examinations were repeated, with use of the same criteria as in 1959, for 167 dentate persons from the original group. Another 28 reported by telephone that they had become edentulous since 1959. This report uses a historical cohort analysis for exploration of the risk factors for tooth loss, both total and partial, over the 28-year period. Over that time, the edentulous lost an average of 18.0 teeth $195 \%$ confidence interval $15.5,20.7)$, whereas the age-matched 90 dentate persons lost only $3.2(2.2,4.2)$ teeth each. Descriptive data showed the edentulous to have higher baseline scores for plaque, calculus, and gingivitis, and a higher proportion of them smoked, though only loss of periodontal attachment (LPA) of $4 \mathrm{~mm}$ or more, early loss of first molars, and educational attainment were significant risk factors in regression analysis. Odds ratios for these three variables were $4.0(1.2,12.8)$, $2.0(1.3,3.1)$, and $0.6(0.4,0.9)$, respectively. The strongest risk factors for partial tooth loss among 116 dentate persons were baseline gingivitis (which was correlated with LPA of $4 \mathrm{~mm}$ or more) and the baseline number of teeth present, with odds ratios of $2.4(1.2,5.2)$ and $0.8(0.7,1.0)$, respectively. While the analysis had to be carried out without caries data, it was concluded that total tooth loss is a social-behavioral issue as much as it is disease-related. Social-behavioral factors were less clearly related to partial tooth loss in dentate persons; oral disease characteristics were the most prominent risk factors for partial tooth loss.

\section{J Dent Res 69(5):1126-1130, May, 1990}

\section{Introduction.}

In 1956, the Department of Epidemiology, University of Michigan, arranged with the people of Tecumseh, Michigan, to conduct a series of longitudinal studies on factors related to their health status. Tecumseh thus joined Framingham, Massachusetts (noted for the studies on cardiovascular conditions), as one of the two communities in the United States whose willingness to serve as a "community laboratory" has yielded information of great value.

As part of the Tecumseh studies, Jamison (1960) recorded the periodontal status of 550 dentate residents of the community in 1959. This survey was intended to be the first in a longitudinal series for the study of the natural history of periodontal diseases, but unfortunately, the proposed follow-up studies were never funded. In 1987, however, the opportunity arose for us to return to Tecumseh, and so in that year, some members of the original group were examined again, 28 years after the first examinations. The incidence of periodontal conditions in this group has been previously reported (Ismail et al., 1990).

This paper uses a historical cohort analysis to identify risk factors for total and partial tooth loss among those examined in 1959 and 1987.

Received for publication August 14, 1989

Accepted for publication December 6, 1989

This study was supported by NIDR Grant No. DE 08051.

\section{Materials and methods.}

Study conditions and examination criteria were described in the previous report (Ismail et al., 1990), and so will be touched on only briefly here. Of the original 526 surviving examinees, data were collected from 195 persons who were found to be little different from the original group in baseline dental characteristics (Table 1). Out of 195, 167 were dentate and clinically examined, although two of them declined a periodontal examination. Another 28 reported that they were edentulous. The edentulous were not examined, though they did provide questionnaire information by telephone.

Examinations were carried out over a two-week period in November, 1987. Records from the three examiners were pooled. Examinations were conducted in the medical office building in which the Tecumseh studies are based, with use of portable A-dec chairs and Rolux fiber-optic lights. Clinical data were entered directly into portable computers at chairside, with use of direct-entry programs prepared especially for this study. Teeth recorded as missing in 1959 were entered into the 1987 records prior to examination, so that inconsistent identification of teeth could be avoided. Teeth were considered missing if no trace of crown or root was visible, and were so recorded regardless of whether a fixed or removable prosthesis was in place. Radiographs were not taken. Caries status was not recorded because caries data from baseline were not available.

Michigan \#0 periodontal probes were used for the periodontal assessments, the same type of probes used by Jamison (1960). The dental examination measured loss of periodontal attachment (LPA) at four sites in each tooth, as described by Ramfjord (1959). Both the 0-3 calculus scale and the 0-3 gingivitis scale were also as described by Ramfjord (1959). Plaque deposits were measured by the Plaque Index (Löe, 1967).

Statistical analysis. - Analysis was carried out in two separate sections: (a) comparison of the 28 persons who became edentulous between 1959 and 1987 with 90 age-matched controls who were still dentate in 1987, and (b) comparisons among 116 dentate persons (those who had erupted all permanent teeth in 1959, except for third molars) in three categories of teeth lost between 1959 and 1987 . These categories were zero teeth lost $(n=46)$, from one to four teeth lost $(n=45)$, and five or more teeth lost $(n=25)$, and were based upon the distribution shown in the Fig. We looked at dividing tooth loss by categories that might have an obvious effect on function, such as loss of opposing molars, but numbers in these categories were too small for useful analysis. Third molars were omitted from all analyses because they were not recorded in 1959 . "The edentulous" are the 28 who were dentate at the 1959 baseline, but who subsequently lost all teeth prior to 1987 . Because all participants were part of the general health studies in Tecumseh, we were able to obtain some additional demographic and general health data from the 1959 database. These were educational levels of respondent and head of household, smoking status, family size, hypertension, and hyperglycemia.

Statistical analysis: Total tooth loss. -The 28 edentulous persons had a mean baseline age of 34.9 years $(95 \%$ confidence interval $31.6,38.1$ ), while the 165 dentate persons from 
TABLE 1

MEAN BASELINE DENTAL CHARACTERISTICS (1959) FOR 526 TECUMSEH EXAMINEES BY RESIDENCY STATUS IN 1987 (95\% CONFIDENCE INTERVALS)

\begin{tabular}{|c|c|c|c|}
\hline \multirow[b]{2}{*}{ Dental Characteristics } & \multicolumn{3}{|c|}{ Residence Status ${ }^{1}$ in 1987} \\
\hline & $\begin{array}{c}\mathrm{A} \\
\mathrm{n}=201\end{array}$ & $\begin{array}{c}\text { B } \\
\pi=195\end{array}$ & $\begin{array}{c}C \\
n=130\end{array}$ \\
\hline Missing Teeth & $2.97(2.35,3.58)$ & $3.15(2.47,3.83)$ & $2.61(1.94,3.28)$ \\
\hline Plaque Index & $1.62(1.54,1.70)$ & $1.60(1.52,1.68)$ & $1.61(1.52,1.70)$ \\
\hline Gingival Index & $1.54(1.46,1.62)$ & $1.53(1.45,1.61)$ & $1.56(1.46,1.66)$ \\
\hline LPA $^{2}$ Buccal Sites & $0.57(0.42,0.72)$ & $0.46(0.32,0.60)$ & $0.53(0.37,0.69)$ \\
\hline LPA $^{2}$ Disto-buccal Sites & $0.93(0.73,1.13)$ & $0.75(0.56,0.95)$ & $0.75(0.54,0.96)$ \\
\hline LPA $^{2}$ Mesio-buccal Sites & $0.88(0.69,1.07)$ & $0.73(0.54,0.92)$ & $0.73(0.51,0.95)$ \\
\hline LPA $^{2}$ Lingual Sites & $0.52(0.38,0.66)$ & $0.52(0.37,0.67)$ & $0.53(0.36,0.70)$ \\
\hline
\end{tabular}

whom all clinical data were available averaged 22.4 years $(95 \%$ C.I. 20.7, 24.3). The baseline age-range of the 28 edentulous was 19-54 years, so to avoid age-confounding, we selected those from the same age range among the dentate $(n=90)$. Analysis then compared this group of 90 dentate persons with the 28 edentulous. The remaining difference between the groups in mean baseline age, $34.9(31.6,38.1)$ years compared with $31.5(30.0,33.1)$, was small enough so that age-confounding could be avoided on the other variables being tested. In addition, the $95 \%$ confidence interval for the difference included zero $(-6.8,0.2)$, so the difference was not considered statistically significant.

Descriptive comparisons and bivariate analyses on baseline parameters were made between edentulous and dentate persons, followed by logistic regression, for identification of the baseline risk factors for eventual total tooth loss. Where LPA is presented as number of teeth affected per person, means were weighted for the number of teeth present in the mouth. In the regression analyses, independent variables tested were age, education, family size, hypertension, hyperglycemia, smoking, teeth present at baseline, number of first molars lost at baseline, baseline measures of plaque, gingivitis, calculus, and numbers of teeth and sites per person with LPA of $4 \mathrm{~mm}$ or more, and $6 \mathrm{~mm}$ or more.

Statistical analysis: Partial tooth loss. -Descriptive and bivariate analyses compared the three categories of tooth loss. For logistic regression analysis, comparisons were made between dentate persons who had lost at least one tooth over the 28 years and those who had lost no teeth. The same independent variables used for the total tooth loss analyses were used in the regression models. In the regression analysis, the 116 individuals were categorized into three strata for gingivitis, based on their GI scores. These strata were (a) GI score < 1.0 , $\mathrm{n}=23$; (b) GI score 1.0 to $<2.0, \mathrm{n}=75$; and (c) GI score $>2.0, \mathrm{n}=18$.

In this report, we have departed from the traditional use of $p$ values to estimate statistical significance and use confidence intervals (CI) instead. Cl's were derived as described by Snedecor and Cochran (1967). The CI values mean that in 95\% of all possible samples, the interval will cover the true population estimate. The use of $95 \%$ CI's provides an idea of the magnitude of the effect and the inherent variability of the estimate, which $p$ values do not, and the interval can also be used as a surrogate for statistical significance (Rothman, 1986).

\section{Results.}

Total tooth loss. - During the 28-year period, 28 of the 195 (14.4\%) of the follow-up participants became edentulous. Ta- ble 2 shows descriptive data on tooth loss over 28 years for the edentulous and the dentate, as well as baseline data on plaque, gingivitis, calculus, and LPA. Major differences in the extent of tooth loss are obvious, and the oral health measures show that the edentulous had higher baseline scores for plaque and calculus, as well as more extensive LPA. In addition to the data in Table $2,53.6 \%$ of the edentulous at baseline had at least one tooth with LPA of $6 \mathrm{~mm}$ or more, compared with $7.7 \%$ of the dentate.

In 1987, there was no relationship between dentate/edentulous status and family size, baseline hypertension, or hyperglycemia. But there was a difference in smoking habits at baseline, with $71 \%$ of the edentulous having reported in 1959 that they were smokers, compared with $36 \%$ of the dentate. Dentate persons were of higher educational attainment than the edentulous, with $12.7 \%$ of the dentate having some college education, compared with none of the edentulous. At the other end of the scale, $24 \%$ of the edentulous had fewer than eight years of education, compared with $8.1 \%$ of the dentate.

Odds ratios were calculated on the probabilities for those who had lost more first molars at baseline to become edentulous, relative to those who had lost fewer. The loss of first molars at baseline was treated as the "exposure" for this analysis. These odds ratios, as well as those which took baseline LPA measures as the exposure variable, are listed in Table 3.

Logistic regression analysis permitted estimation of the joint effect of the various risk factors listed earlier. Family size, hypertension, and hyperglycemia did not reach statistical significance in the final model, nor did smoking. With dentate persons as the reference group, the strongest risk factors tested were number of sites per person with LPA of $4 \mathrm{~mm}$ or more,

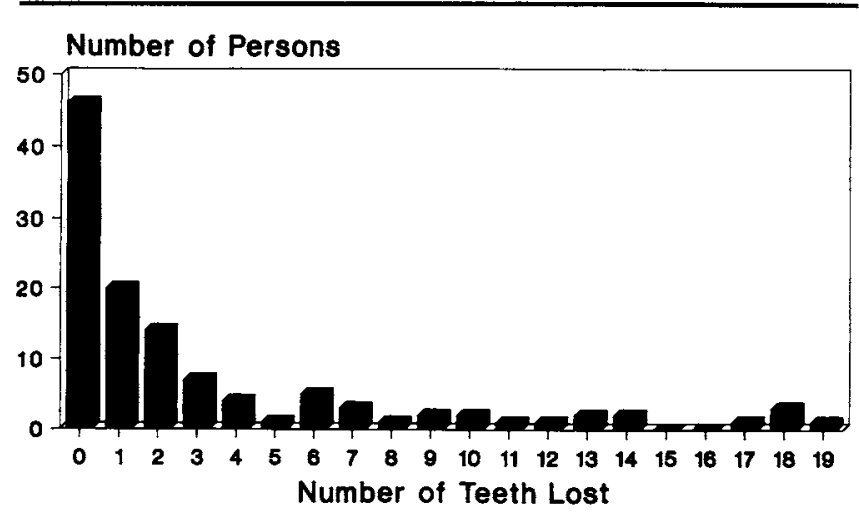

Fig.-Distribution of tooth loss among 116 dentate persons over 28 years. 
TABLE 2

ORAL HEALTH MEASURES (BY DENTATE OR EDENTULOUS STATUS IN 1987) FOR PERSONS AGED 19-54 IN TECUMSEH, MICHIGAN

\begin{tabular}{|c|c|c|c|c|}
\hline & \multicolumn{2}{|c|}{ Dentate $(n=90)$} & \multicolumn{2}{|c|}{ Edentulous $(n=28)$} \\
\hline & Mean & 95\% Conf. Intervals & Mean & $95 \%$ Conf. Intervals \\
\hline Teeth present in 1959 & 24.7 & $(23.9,25.5)$ & 18.1 & $(15.5,20.7)$ \\
\hline Teeth present in 1987 & 21.5 & $(20.1,22.9)$ & - & \\
\hline Teeth lost over 28 years & 3.2 & $(2.2,4.2)$ & 18.1 & $(15.5,20.7)$ \\
\hline \multicolumn{5}{|l|}{ Baseline Measures: } \\
\hline Plaque Index & 1.3 & $(1.2,1.4)$ & 1.7 & $(1.4,2.0)$ \\
\hline Gingival Index & 1.4 & $(1.3,1.5)$ & 2.2 & $(2.0,2.4)$ \\
\hline Calculus Index & 0.6 & $(0.5,0.7)$ & 1.6 & $(1.3,1.9)$ \\
\hline \multicolumn{5}{|l|}{ Teeth per person ${ }^{1}$} \\
\hline with $\mathrm{LPA}^{2} \geq 4 \mathrm{~mm}$ & 1.0 & $(0.4,1.6)$ & 7.9 & $(5.0,10.8)$ \\
\hline \multicolumn{5}{|l|}{ Teeth per person ${ }^{1}$} \\
\hline with $\mathrm{LPA}^{2} \geq 6 \mathrm{~mm}$ & 0.3 & $(-0.1,0.7)$ & 3.7 & $(1.4,6.0)$ \\
\hline
\end{tabular}

(1) Weighted for number of teeth present.

${ }^{(2)}$ Loss of periodontal attachment.

number of first molars lost at baseline, and educational level of the respondent, as shown in Table 4. Because loss of first molars at baseline is a five-strata variable, while periodontal sites per person in this model is a two-strata variable, both variables can be considered equally prominent risk factors for total tooth loss, even though one odds ratio is twice the other.

Partial tooth loss among the dentate. - Baseline descriptive measures of age and oral health status at baseline for the three tooth-loss groups are given in Table 5. While there was a trend toward increasing age with greater tooth loss, there were no statistically significant differences. (Statistically significant differences can be assumed when Cl's do not overlap.) There were statistically significant differences between the extremes in baseline teeth present, gingival index scores, and calculus scores, but none in plaque index or LPA measures, although trends again are evident. No differences between the tooth loss groups were seen in family size, hypertension, hyperglycemia, educational attainment, and baseline smoking history (this latter group of variables was not tabulated).

In the logistic regression analysis (Table 6), which set the reference group as zero tooth loss over the 28 years, only the number of teeth present at baseline and baseline gingivitis (as a three-strata variable) were significant risk factors. Gingivitis was correlated with LPA of $4 \mathrm{~mm}$ or more (Spearman $\mathrm{r}=$ $0.47, p<0.001$ ), which may explain its statistical significance in this model.

\section{Discussion.}

This study was designed as a historical cohort, meaning that while a cohort was followed and various outcomes recorded, the outcomes (in this case tooth loss) had all occurred prior to

TABLE 3

ODDS RATIOS FOR VARIOUS BASELINE RISK FACTORS IN TOTAL TOOTH LOSS OVER 28 YEARS

\begin{tabular}{lrc}
\hline \hline \multicolumn{1}{c}{ Baseline Risk Factor } & $\begin{array}{c}\text { Odds } \\
\text { Ratio }\end{array}$ & 95\% Conf. Interval \\
\hline At lcast one site LPA* $\geq 4 \mathrm{~mm} v s$. none & 9.3 & $(3.5,24.7)$ \\
At least one site LPA $\geq 6 \mathrm{~mm} v s$. none & 13.7 & $(4.7,39.9)$ \\
Lost 1.4 first molars $v s$. none & 4.2 & $(1.3,13.0)$ \\
Lost 2.4 first molars $v s .0-1$ & 4.9 & $(1.9,12.8)$ \\
Lost 3-4 first molars $v s .0-2$ & 5.0 & $(2.0,12.0)$ \\
Lost 4 first molars $v s .0-3$ & 9.4 & $(2.8,31.0)$ \\
Lost 4 first molars $v s$. none & 18.5 & $(4.2,82.0)$ \\
\hline
\end{tabular}

"Loss of periodontal attachment. the start of the investigation (Rothman, 1986). This study design does not permit firm cause-and-effect conclusions to be drawn, though it can produce hypotheses for further investigation. Like the other retrospective design in epidemiology (case-control), a historical cohort study has the advantage of being quicker and less expensive than prospective studies. Where clear and obvious differences are discerned, the hypotheses are strengthened (Schlesselman, 1982). The epidemiological quest for determinants of conditions that take years to develop, or are uncommon, or both, is more efficiently carried out with retrospective than with prospective designs. The study of factors leading to tooth loss, oral cancers, chronic facial pain, temporomandibular disorders, and perhaps adult periodontitis, all fall into this category.

Regression analysis is a powerful tool in helping us to understand relationships, though its optimum use is still evolving. In real-life situations, risk factors interact with each other as contributors in a causal pathway. Because the bivariate analysis of each risk factor with outcome does not permit evaluation of these interactions, bivariate analyses should be taken as only a first step, chiefly to help generate hypotheses. Regression analysis focuses on determining which risk factors are important, the relative influence of each, and the predictive value of all of them together. In epidemiology, moreover, the type of link between the independent variables is also of special interest because variables acting together in a multiplicative way produce a greater effect on outcome than when they act additively. The iterative way in which logistic regression models are developed provides a means for determination of which link between the independent variables in the model is best

\section{TABLE 4}

ODDS RATIOS ON PROBABILITY OF BECOMING EDENTULOUS FOR THREE RISK FACTORS IN BEST-FITTING LOGISTIC REGRESSION MODEL

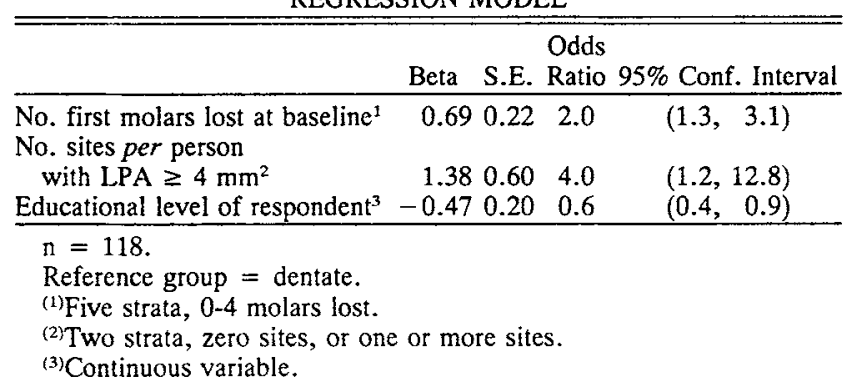


TABLE 5

ORAL HEALTH MEASURES FOR DENTATE PERSONS IN TECUMSEH, MICHIGAN, BY THREE CATEGORIES OF TOOTH LOSS

\begin{tabular}{|c|c|c|c|}
\hline \multirow[b]{2}{*}{ Baseline Mcasures } & \multicolumn{3}{|c|}{$\begin{array}{c}\text { Number of Teeth Lost 1959-87 } \\
\left(\text { Mean and } 95 \% \mathrm{Cl}^{1}\right)\end{array}$} \\
\hline & None $(n=46)$ & $\frac{\text { Mean and } 95 \% \mathrm{Cl}^{1}}{1-4(\mathrm{n}=45)}$ & $5+(n=25)$ \\
\hline Age in Years & $26 \quad(23.3,28.6)$ & $28 \quad(26.4,31.5)$ & $30 \quad(26.1,34.3)$ \\
\hline No. Tecth Present & $26.4(26.0,27.0)$ & $24.7(23.4,26.0)$ & $23.9(22.4,25.4)$ \\
\hline Plaque Index & $1.4(1.3,1.6)$ & $1.4(1.3,1.5)$ & $1.5(1.4,1.7)$ \\
\hline Gingival Index & $1.2(1.1,1.4)$ & $1.4(1.2,1.6)$ & $1.7(1.6,2.0)$ \\
\hline Calculus Index & $0.4(0.2,0.5)$ & $0.5(0.3,0.7)$ & $1.0(0.7,1.3)$ \\
\hline \multicolumn{4}{|l|}{ Teeth per person ${ }^{2}$} \\
\hline with $\mathrm{LPA}^{3} \geq 4 \mathrm{~mm}$ & $0.4(0,1.2)$ & $0.6(0.2,1.2)$ & $2.2(0.4,4.0)$ \\
\hline \multicolumn{4}{|l|}{ Teeth per person ${ }^{2}$} \\
\hline with $\mathrm{LPA}^{3} \geq 6 \mathrm{~mm}$ & $0.1(0,0.3)$ & $0.2(0,0.3)$ & $0.9(0,2.5)$ \\
\hline
\end{tabular}

supported by the data. In the present analysis, the independent variables in the edentulous model had a multiplicative effect on the outcome, whereas in the partial tooth loss model, they had an additive effect. This suggests that the joint effect of the independent variables in the edentulous model was stronger, when compared with those in the partial tooth loss model. "Stronger" here means a greater probability of the outcome being achieved. The research issue of how to use regression analysis most effectively in epidemiology, as mentioned, deserves continued attention.

In their study of elderly people in lowa, Hunt et al. (1988) found that the distribution of tooth loss over an 18-month period was highly skewed. The same was true in Tecumseh over a period of 28 years; the $14.4 \%$ of the follow-up population who became edentulous accounted for $64 \%$ of all teeth lost in that period. Among those who remained dentate, $13.8 \%$ lost $60.2 \%$ of all teeth lost in that group. It is tempting for us to conclude that a minority is "susceptible" to extensive tooth loss, just as a minority appears susceptible to severe manifestations of caries (US Public Health Service, 1981; Graves et al., 1986) and periodontal disease (Löe et al., 1986; US Public Health Service, 1987), but tooth loss is not a disease. The question that arises is the extent to which this skewed distribution reflects social factors, as well as the underlying diseases. Recent studies seeking reasons for tooth loss have not probed this issue (Ainamo et al., 1984; Bouma et al., 1985; Cahen et al., 1985; Kay and Blinkhorn, 1986; Bailit et al., 1987; Manji et al., 1988; Hunt et al., 1988; Chauncey et al., 1989; Niessen and Weyant, 1989). Their principal finding is that periodontal disease is not as important a reason for tooth loss as once thought, but many questions on the relative impact of disease, patient attitudes, and treatment philosophy on tooth loss remain unanswered (Weintraub and Burt, 1985).

The relationship between smoking and tooth loss was not totally clear in this population. In the bivariate analysis, a higher proportion of edentulous than dentate persons reported

\section{TABLE 6}

ODDS RATIOS ON PROBABILITY OF LOSING TEETH, FOR TWO RISK FACTORS IN BEST-FITTING LOGISTIC MODEL

\begin{tabular}{lcccc}
\hline & Beta & S.E. & Odds \\
& Ratio & $95 \% \mathrm{Cl}$ \\
\hline Teeth present at baseline & -0.20 & 0.08 & 0.8 & $(0.7,1.0)$ \\
Gingivitis at baseline $^{1}$ & 0.89 & 0.38 & 2.4 & $(1.2,5.2)$ \\
\hline
\end{tabular}

$\mathrm{n}=116$.

Reference group $=$ zero teeth lost 1959-87.

(1) Three-strata variable (see text). at baseline that they smoked, but the effect of smoking disappeared in the regression model. This is most likely because smoking is closely associated with one or more of the other independent variables, such as education or gingivitis, and hence did not exert an independent effect in our regression model. Whether smoking is a direct cause of tooth loss, presumably through periodontitis, is not yet clear, though a recent Swedish report concluded that it is (Ahlqwist et al., 1989). An alternative explanation is that the health values of smokers are lower than those of non-smokers, so that they may not make the same efforts to avoid tooth loss that non-smokers would. If indeed there is a link between early molar loss and attitudes toward tooth retention, then in this case the strong effect of early loss of molars in the model may have overwhelmed any effect of smoking.

From the results of this analysis, a profile of those who became edentulous over the period of study, compared with those who did not, suggests itself. Edentulous persons were more likely to (a) have suffered early loss of first molars, (b) be of lower educational attainment, and (c) have more calculus, gingivitis, and LPA during their dentate life. In this study, the edentulous also tended to have more plaque, and their ranks included more smokers than were found among the dentate. This profile suggests that the poorer oral health status recorded at baseline could just as easily be a reflection of low interest in oral health as a cause per se of subsequent total tooth loss. While caries data would have been a useful addition in our analyses, it is likely that early loss of first molars acted as a surrogate for severe caries. It would be illuminating to know how much the attitudes of patient and dentist contributed to the loss of the rest of the dentition. Some tantalizing hints emerged when the edentulous persons were asked the reason all their teeth were removed. Statements such as "it was time they came out", "the dentist said they should all come out", and "I was sick of them" can hardly be used in scientific analysis, though they do foster speculation.

Gingivitis emerged as the most prominent risk factor for partial tooth loss. As mentioned earlier, gingivitis was significantly correlated with LPA of $4 \mathrm{~mm}$ or more, which could explain its role here. As was suggested with the analyses on edentulous people, gingivitis could also be a marker for people who have less interest in their oral health, and hence may have an indirect role in the regression model. Age and educational attainment were not significant in the regression model. Age and educational attainment were not significant in the regression analyses for partial tooth loss.

Without venturing here into a discussion of what constitutes periodontal disease, we suggest that $4 \mathrm{~mm}$ is the minimum 
LPA that should be considered as periodontitis in epidemiological studies, a statement based largely on statistical distributions (Burt, 1990).

These findings suggest that total tooth loss is not just a disease-related extension of partial tooth loss, but rather a different phenomenon with social-attitudinal factors playing a prominent part. Achievement of the goal of reduction of total tooth loss even further will demand a better understanding of the social-attitudinal factors involved, as well as further research on the role of oral (and perhaps systemic) disease in tooth loss. Oral diseases appear to be the major risk factors for partial tooth loss, though our results suggest that social and behavioral factors also play a role.

\section{Acknowledgments.}

We thank Drs. Stevo Julius and David Schottenfeld for their generosity in letting us use the facility for the Tecumseh Community Study. The study could not have been carried out without the work of Virginia Cline and the late Alice Exelby who contacted participants and arranged examination schedules, or without the generous cooperation of the people of Tecumseh.

\section{REFERENCES}

AHLQWIST, M.; BENGTSSON, C.; HOLLENDER, L.; LAPIDUS, L.; and OSTERBERG, T. (1989): Smoking Habits and Tooth Loss in Swedish Women, Community Dent Oral Epidemiol 17:144147.

AINAMO, J.; SARKKI, L.; KUHALAMPI, M.L.; PALOLAMPI, L.; and PIIRTO, O. (1984): The Frequency of Periodontal Extractions in Finland, Community Dent Health 1:165-172.

BAILIT, H.L.; BRAUN, R.; MARYNIUK, G.A.; and CAMP, P. (1987): Is Periodontal Disease the Primary Cause of Tooth Extraction in Adults?, $J$ Am Dent Assoc 114:40-45.

BOUMA, J.; SCHAUB, R.M.H.; and VAN DE POEL, A.C.M. (1985): Periodontal Status and Total Tooth Extraction in a Medium-sized City in the Netherlands, Community Dent Oral Epidemiol 13:323-327.

BURT, B.A. (1990): The Distribution of Pcriodontitis in the Industrialised Countries. In: Markers of Disease Susceptibility and Activity for Periodontal Diseases, N. W. Johnson, Ed., London: Cambridge University Press, in press.

CAHEN, P.M.; FRANK, R.M.; and TURLOT, J.C. (1985): A Survey of the Reasons for Dental Extractions in France, $J$ Dent Res 64:1087-1093.
CHAUNCEY, H.H.; GLASS, R.L.; and ALMAN, J.E. (1989): Dental Caries. Principal Cause of Tooth Extraction in a Sample of US Male Adults, Caries Res 23:200-205.

GRAVES, R.C.; BOHANNAN, H.M.; DISNEY, J.A.; STAMM, J.W.; BADER, J.D.; and ABERNATHY, J.R. (1986): Recent Dental Caries and Treatment Patterns in U.S. Children, J Publ Health Dent 46:23-29.

HUNT, R.J.; HAND, J.S.; KOHOUT, F.J.; and BECK, J.D. (1988): Incidence of Tooth Loss among Elderly lowans, Am J Publ Health 78:1330-1332.

ISMAIL, A.I.; MORRISON, E.C.; BURT, B.A.; CAFFESSE, R.G.; and KAVANAGH, M.T. (1990): Natural History of Periodontal Disease in Adults. Findings from the Tecumseh Periodontal Disease Study, 1959-87, J Dent Res 69:430-435.

JAMISON, H.C. (1960): Prevalence and Severity of Periodontal Disease in a Sample of a Population, Ann Arbor, MI: Doctoral Dissertation, University of Michigan, pp. 1-153.

KAY, E.J. and BLINKHORN, A.S. (1986): The Reasons Underlying the Extraction of Teeth in Scotland, Br Dent $J$ 160:287-290.

LÖE, H. (1967): The Gingival Index, Plaque Index, and the Retention Index Systems, $J$ Periodontol 38:610-616.

LÖE, H.; ANERUD, A.; BOYSEN, M.; and MORRISON, E.C. (1986): Natural History of Periodontal Disease in Man. Rapid, Moderate, and No Loss of Attachment in Sri Lankan Laborers 14 to 46 Years of Age, $J$ Clin Periodontol 13:431-440.

MANJI, F.; BAELUM, V.; and FEJERSKOV, O. (1988): Tooth Mortality in an Adult Rural Population in Kenya, $I$ Dent Res $67: 496-500$

NIESSEN, L.C. and WEYANT, R.J. (1989): Causes of Tooth Loss in a Veteran Population, $J$ Publ Health Dent 49:19-23.

RAMFJORD, S.P. (1959): Indices for Prevalence and Incidence of Periodontal Disease, I Periodontol 30:51-59.

ROTHMAN, K.J. (1986): Modern Epidemiology, Boston: Little, Brown and Company, pp. 119-125 and 60-61.

SCHLESSELMAN, J.J. (1982): Case-Control Studies: Design, Conduct, Analysis, New York: Oxford University Press, pp. 1025.

SNEDECOR, G.W. and COCHRAN, W.G. (1967): Statistical Methods, 6th ed., Ames, IA: lowa State University Press, pp. 61-62.

U.S. PUBLIC HEALTH SERVICE, NATIONAL INSTITUTE OF DENTAL RESEARCH (1981):The Prevalence of Dental Caries in United States Children, Bethesda, MD: NIH Publication No. 82-2245.

U.S. PUBLIC HEALTH SERVICE, NATIONAL INSTITUTE OF DENTAL RESEARCH (1987): Oral Health of United States Adults, Bethesda, MD:NIH Publication No. 87-2868.

WEINTRAUB, J.A. and BURT, B.A. (1985): Tooth Loss in the United States, $J$ Dent Educ 49:368-376. 